\title{
Assessment of Quality of Life in Patients with Acute Appendicitis after a Minimally Invasive Approach
}

\author{
Alexei L. Charyshkin, PhD, ScD*; Maksim M. Yartsev \\ Institute of Medicine, Ecology and Physical Education of Ulyanovsk State University \\ Ulyanovsk, the Russian Federation
}

\begin{abstract}
The leading indicator of a successful outcome of surgical intervention is generally recognized as an assessment of QL, which includes the physical, psychological, emotional and social functioning of a person. The results of the QL study after 6 months and 1 year following the appendectomy showed significantly higher total physical and mental health indicators in patients after minilaparotomy by the proposed method. Long-term results 1 year after appendectomy in these patients demonstrate the stability of the restored clinical parameters. (International Journal of Biomedicine. 2018;8(2):139-141.)
\end{abstract}

Key Words: acute appendicitis $\bullet$ surgery $\bullet$ minilaparotomy $\bullet$ quality of life

\section{Abbreviations}

BP, bodily pain; GH, general health; MH, mental health; PF, physical functioning; QL, the quality of life; RP, role-physical functioning; RE, role emotional; SF-36, the 36-Item Short-Form Health Survey; SF, social functioning; VT, vitality.

\section{Introduction}

In modern surgery for diseases of the abdominal cavity, minimally invasive surgical approaches are used-in particular, in patients with acute appendicitis. ${ }^{(1-5)}$ Minimally invasive surgical interventions are aimed at reducing the trauma of surgery, reducing the duration of hospitalization and rehabilitation of patients, and improving the cosmetic effect. ${ }^{(6-10)}$ To perform an appendectomy, minimally invasive approaches to the abdominal cavity include minilaparotomy and video laparoscopy. ${ }^{(11-15)}$

The leading indicator of a successful outcome of surgical intervention is generally recognized as an assessment of QL, which includes the physical, psychological, emotional and social functioning of a person. ${ }^{(7)}$ Studying QL in patients after surgical interventions promotes the identification of positive and negative moments of those interventions in patients with various pathologies. ${ }^{(7-9)}$ Despite these benefits, the available

*Corresponding author: Prof. Alexei L. Charyshkin, PhD, ScD, Head of the Faculty Surgery Department, Institute of Medicine, Ecology and Physical Education, Ulyanovsk State University. Ulyanovsk, the Russian Federation.E-mail: charyshkin@yandex.ru literature lacks sufficient descriptions of the QL evaluation in patients after appendectomy by a minimally invasive approach.

The aim of our research was to study the indicators of QL in patients with acute appendicitis who were operated on by minilaparotomy.

\section{Materials and Methods}

The study included 220 patients with acute appendicitis aged 18 years and over (both sexes), with consent for surgical treatment, who underwent surgical treatment in the surgical department at the Nikolaev district hospital of the Ulyanovsk region in the period from 2008 to 2017. Exclusion criteria were age less than 18 years, acute pathological conditions requiring intensive care, and oncological diseases.

The study was conducted in accordance with ethical principles of the Declaration of Helsinki and approved by the by Ethics Committees at our institutions. All patients underwent general clinical and laboratory, radiographic, endoscopic, ultrasound, histological methods of investigation; whenever required, echocardiographic study was carried out.

All patients were divided into 2 groups. The groups were comparable with respect to age and sex. Group 1 included 
140 patients who underwent appendectomy by the traditional method of minilaparotomy. Group 2 included 80 patients who underwent appendectomy by the developed method of a minimally invasive approach. ${ }^{(8)}$

The proposed minimally invasive approach included: a) a cut of the skin in the right iliac region from a point located between the outer and middle third parts of the line connecting the umbilicus with the right anterior superior iliac spine, down and perpendicular to the mentioned line (from $2 \mathrm{~cm}$ to $4 \mathrm{~cm}$ in length); and b) dissection of the aponeurosis of the outer oblique abdominal muscle along the aponeurotic fibers. It is characteristic of this method that in the upper corner of the wound the incision of the aponeurosis of the external oblique abdominal muscle is deflected upwards parallel to the edge of the rectus abdominis muscle, up to $3 \mathrm{~cm}$ in length; and in the lower corner of the wound, the incision of the aponeurosis of the external oblique abdominal muscle is deflected downwards parallel to the edge of the rectus abdominis muscle, up to $3 \mathrm{~cm}$ in length. Muscles are stretched by hooks along the length of the wound, and then the peritoneum is opened and an appendectomy is performed. ${ }^{(8)}$ An appendectomy was performed in all patients with the use of an original retractor. ${ }^{(9)}$

In the postoperative period, adequate infusion therapy was performed. The water-electrolyte balance was corrected under the control of the content of potassium, calcium, and sodium ions in the blood plasma. For parenteral nutrition, protein hydrolysates and a glucose-insulin mixture were administered. To prevent purulent complications, cephalosporins of the third generation were intravenously prescribed.

Statistical analysis was performed using the statistical software «Statistica». (v6.0, StatSoft, USA). All values are presented as mean $\pm \mathrm{SEM}$. The inter-group comparisons were performed using Student's t-test. A probability value of $P<0.05$ was considered statistically significant.

\section{Results and Discussion}

The QL indicators were assessed at 6 months and 1 year after surgery, using SF-36. QL indicators were studied in $120(85.7 \%)$ patients in Group 1 and in $72(90 \%)$ patients in Group 2 (Table 1 and 2).

The results of the QL study after 6 months and 1 year following the appendectomy showed significantly higher total physical and mental health indicators in patients after minilaparotomy by the proposed method. Long-term results 1 year after appendectomy in these patients demonstrate the stability of the restored clinical parameters (i.e. retain the same improved values as were observed 6 months after the performed operation). Obviously, the positive effect obtained is the result of using minilaparotomy by the developed method, which reduces the traumatic nature of surgical intervention, helps to reduce the development of complications, and improves QL.

The study of QL is one of the leading indicators of the effectiveness of surgical treatment and the evaluation of the modern minimally invasive technologies being introduced. The proposed method of minilaparotomy allows performing surgical intervention in emergency surgery, acting as an alternative to video laparoscopy in some non-standard situations.

Table 1

SF-36 parameters in two groups 6 months after surgery

\begin{tabular}{|l|c|c|c|}
\hline \multicolumn{1}{|c|}{ SF-36 } & Variable & $\begin{array}{c}\text { Group 1 } \\
(\mathrm{n}=120)\end{array}$ & $\begin{array}{c}\text { Group 2 } \\
(\mathrm{n}=72)\end{array}$ \\
\hline \multirow{4}{*}{ Physical domain } & $\mathrm{PF}$ & $81.1 \pm 1.3$ & $85.8 \pm 1.5^{*}$ \\
\cline { 2 - 4 } & $\mathrm{RP}$ & $69.2 \pm 1.4$ & $75.4 \pm 1.7^{*}$ \\
\cline { 2 - 4 } & $\mathrm{BP}$ & $68.1 \pm 1.4$ & $73.2 \pm 1.7^{*}$ \\
\cline { 2 - 4 } & $\mathrm{GH}$ & $53.2 \pm 1.6$ & $59.7 \pm 1.6^{*}$ \\
\hline \multirow{4}{*}{ Psychological domain } & $\mathrm{VT}$ & $54.1 \pm 2.0$ & $60.4 \pm 1.8^{*}$ \\
\cline { 2 - 4 } & $\mathrm{SF}$ & $62.2 \pm 1.7$ & $74.1 \pm 2.0^{*}$ \\
\cline { 2 - 4 } & $\mathrm{RE}$ & $68.3 \pm 1.4$ & $73.4 \pm 1.3^{*}$ \\
\cline { 2 - 4 } & $\mathrm{MH}$ & $53.1 \pm 1.8$ & $63.2 \pm 1.5^{*}$ \\
\hline
\end{tabular}

*. $P$-value $<0.05$ between groups.

Table 2.

SF-36 parameters in two groups one year after surgery

\begin{tabular}{|l|c|c|c|}
\hline \multicolumn{1}{|c|}{ SF-36 } & Variable & $\begin{array}{c}\text { Group 1 } \\
(\mathrm{n}=120)\end{array}$ & $\begin{array}{c}\text { Group 2 } \\
(\mathrm{n}=72)\end{array}$ \\
\hline \multirow{4}{*}{ Physical domain } & $\mathrm{PF}$ & $82.3 \pm 1.7$ & $86.2 \pm 1.6^{*}$ \\
\cline { 2 - 4 } & $\mathrm{RP}$ & $69.1 \pm 2.1$ & $75.1 \pm 1.8^{*}$ \\
\cline { 2 - 4 } & $\mathrm{BP}$ & $68.1 \pm 1.3$ & $73.2 \pm 1.8^{*}$ \\
\cline { 2 - 4 } & $\mathrm{GH}$ & $53.9 \pm 1.5$ & $59.9 \pm 1.7^{*}$ \\
\hline \multirow{5}{*}{ Psychological domain } & $\mathrm{VT}$ & $54.3 \pm 1.5$ & $60.5 \pm 1.9^{*}$ \\
\cline { 2 - 4 } & $\mathrm{SF}$ & $62.9 \pm 2.2$ & $74.2 \pm 1.9^{*}$ \\
\cline { 2 - 4 } & $\mathrm{RE}$ & $68.5 \pm 1.9$ & $73.5 \pm 2.2^{*}$ \\
\cline { 2 - 4 } & $\mathrm{MH}$ & $53.3 \pm 2.3$ & $63.5 \pm 1.9^{*}$ \\
\hline
\end{tabular}

*. P-value $<0.05$ between groups.

Thus, the developed method of minilaparotomy for performing appendectomy is an expedient and justified direction in minimally invasive surgery. Important advantages of minilaparotomy are the possibility of improving the cosmetic effect, reducing the level of postoperative pain syndrome in combination with a reduction in the duration of inpatient treatment and better indicators of QL. There is no doubt that further investigation of the results of minilaparotomy for appendectomy is necessary.

\section{Conclusion}

The proposed method of minilaparotomy for appendectomy increases the overall physical and mental health indicators in patients in the remote postoperative period in comparison with the traditional minilaparotomy. 


\section{Competing interests} interests.

The authors declare that they have no competing

\section{Sources of Funding}

This study was funded by the Ministry of Education and Science of the Russian Federation (the science project No. 18.7236.2017/BCh).

\section{References}

1. Kriger AG, Fedorov AV. Acute appendicitis. M.: Medpraktika; 2002. [In Russian].

2. Prudkov MI. Basics of minimally invasive surgery. Yekaterinburg: Publishing House of the Ural State University; 2007. [In Russian].

3. Prudkov MI. Clinical recommendations for providing medical care to the population of the Urals Federal District. Yekaterinburg: Publishing House of the Ural State University;2013. [In Russian]. 4. Pugaev AV, Achkasov EE. Acute appendicitis. M.: Triada; 2011. [In Russian].

5. Remizov OV, Maskin SS, Karsanov AM, Vakhotskiy VV, Gudushauri MK. [Possibility of radiation imaging in acute appendicitis]. Medical News of the North Caucasus. 2017;12(1):105-110. doi: 10.14300/mnnc.2017.12031. [Article in Russian].

6. Uteshev NS. Acute appendicitis. Modern methods in diagnosis and treatment of acute appendicitis and its complications. M.:Miklosh; 2010. [In Russian].

7. Faev AA, Yaroschuk SA. [Evaluation of the quality life in patients with acute appendicitis and cholecystitis operated by a single-port access]. Medicine in Kuzbass. 2016;15(2):58-62. [Article in Russian].
8. Caryshkin AL, Yartsev MM. Patent of the Russian Federation, "Method of a minimally invasive approach for appendectomy". (RU \#2612983; priority of 05.11.2016, register. of 03.14.2017; Bull \#8). [In Russian].

9. Caryshkin AL, Bikbaeva KI. [Comparative results of application of the minilaparotomy at patients with sharp cholecystitis]. Modern problems of science and education. 2014;(2). Available from: https://science-education.ru/en/ article/view?id=12262. [Article in Russian].

10. Antoniou SA, Mavridis D, Hajibandeh S, Hajibandeh S, Antoniou GA, Gorter R, et al. Optimal stump management in laparoscopic appendectomy: A network meta-analysis by the Minimally Invasive Surgery Synthesis of Interventions and Outcomes Network. Surgery. 2017;162(5):994-1005. doi: 10.1016/j.surg.2017.07.013

11. Macco S, Vrouenraets BC, de Castro SM. Evaluation of scoring systems in predicting acute appendicitis in children. Surgery. 2016;160(6):1599-1604. doi: 10.1016/j. surg.2016.06.023.

12. Putnam LR, Nguyen LK, Lally KP, Franzini L, Tsao K, Austin MT. A statewide analysis of specialized care for pediatric appendicitis. Surgery. 2015;158(3):787-92. doi: 10.1016/j.surg.2015.05.010.

13. Schoenberg MB, Magdeburg R, Kienle P, Post S, Eisser PP, Kähler G. Hybrid transgastric appendectomy is feasible but does not offer advantages compared with laparoscopic appendectomy: Results from the transgastric appendectomy study. Surgery. 2017;162(2):295-302. doi: 10.1016/j.surg.2017.02.013.

14. Smith MC, Boylan MR, Tam SF, Lee R, Alfonso AE, Sugiyama G. End-stage renal disease increases the risk of mortality after appendectomy. Surgery. 2015;158(3):722-7. doi: 10.1016/j.surg.2015.03.064.

15. Wu JX, Dawes AJ, Sacks GD, Brunicardi FC, Keeler EB. Cost effectiveness of nonoperative management versus laparoscopic appendectomy for acute uncomplicated appendicitis. Surgery. 2015;158(3):712-21. doi: 10.1016/j. surg.2015.06.021. 